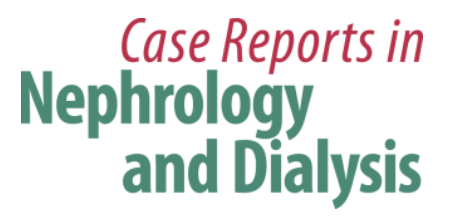

Case Rep Nephrol Dial 2019;9:55-63

DOI: $10.1159 / 000500104$

Published online: May 16, 2019

(C) 2019 The Author(s)

Published by S. Karger AG, Basel

www.karger.com/cnd

This article is licensed under the Creative Commons Attribution-NonCommercial 4.0 International License (CC BY-NC) (http://www.karger.com/Services/OpenAccessLicense). Usage and distribution for commercial purposes requires written permission.

\title{
Single Pass Albumin Dialysis and Plasma Exchange for Copper Toxicity in Acute Wilson Disease
}

\author{
Shireen Bakhsh ${ }^{a, b} \quad$ Chia Wei Teoh ${ }^{a, c} \quad$ Elizabeth A. Harvey ${ }^{a, c}$ \\ Damien G. Noone $e^{a, c}$ \\ aDivision of Nephrology, The Hospital for Sick Children, Toronto, ON, Canada; \\ bDepartment of Paediatrics, Security Forces Hospital, Riyadh, Saudi Arabia; \\ 'Department of Paediatrics, University of Toronto, Toronto, ON, Canada
}

\section{Keywords}

Albumin dialysis - Dialysis - Plasmapheresis - Wilson disease · Copper toxicity · Extracorporeal liver support

\begin{abstract}
Background: Wilson disease (WD) is a disorder of copper metabolism that results in accumulation of copper in tissues. In acute WD, patients present with fulminant hepatic failure, encephalopathy, and hemolytic anemia due to copper release from necrotic hepatocytes. Many will require life-saving liver transplantation. Extracorporeal liver support systems can provide a bridge to transplantation for critically ill patients. We report our experience with 2 patients for whom we used a combination of plasma exchange (PLEX) and single pass albumin dialysis (SPAD), or SPAD alone as a bridge to liver transplantation. Case Reports: A 17-year-old girl (patient 1) and a 12-year-old boy (patient 2) presented with fulminant hepatic failure, hemolytic anemia, and acute kidney injury. Patient 1 received SPAD on days 2 and 3 (total $32 \mathrm{~h}$ ). Serum copper decreased from 22.3 to $15.9 \mu \mathrm{mol} / \mathrm{L}$ (28.7\% decrease), measured after $28 \mathrm{~h}$ of continuous SPAD. She underwent successful liver transplantation on day 4 after presentation.
\end{abstract}




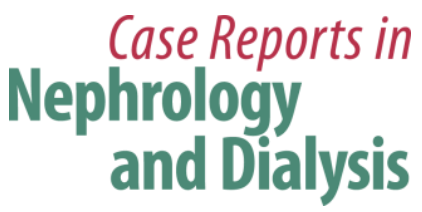

\begin{tabular}{l|l} 
Case Rep Nephrol Dial 2019;9:55-63 \\
\hline DOI: 10.1159/000500104 & $\begin{array}{l}\text { @ 2019 The Author(s). Published by S. Karger AG, Basel } \\
\text { www.karger.com/cnd }\end{array}$
\end{tabular}

Bakhsh et al.: SPAD and PLEX for Copper Toxicity in Wilson Disease

Patient 2 was treated with PLEX on days 1, 3, 4, and 5 and with SPAD on days 3-6. Serum copper decreased from 48.7 to $25.8 \mu \mathrm{mol} / \mathrm{L}$ (47\% decrease) after the first session of PLEX and from 35.5 to $21.5 \mu \mathrm{mol} / \mathrm{L}$ (39.4\% decrease) after the second session. The serum copper level was $16.2 \mu \mathrm{mol} / \mathrm{L}$ after 4 sessions of PLEX (and ongoing SPAD), with an overall $66.7 \%$ reduction in copper levels over 5 days combining both therapies. He underwent successful liver transplantation on day 6. Conclusion: We conclude that SPAD, with or without PLEX, is effective in reducing serum copper levels as a bridge to liver transplantation in WD. PLEX may be more efficient at removing copper but is associated with a rebound increase in copper levels between sessions.

(C) 2019 The Author(s)

Published by S. Karger AG, Basel

\section{Introduction}

Wilson disease (WD) is a rare autosomal recessive disorder of copper metabolism, with mutations in the $A T P 7 B$ gene on chromosome 13 [1]. Clinical manifestations predominantly reflect hepatic injury, but also include neuropsychiatric manifestations and hemolytic anemia [2]. A diagnosis of WD is supported by low ceruloplasmin, elevated hepatic copper, increased urinary copper excretion, and detection of Kayser-Fleischer rings on ophthalmologic examination [3].

Patients with fulminant WD present with liver failure, hepatic encephalopathy, and hemolytic anemia, the last a result of the direct toxicity of copper released from necrotic hepatocytes [4]. Therapy includes chelation with agents such as D-penicillamine and trientine to reduce serum copper levels [5], but this is often limited by the presence of acute kidney injury, which prevents adequate urinary copper removal by chelation. The mortality rate among such patients approaches $100 \%$ without a liver transplant [6].

Copper is predominantly incorporated into ceruloplasmin, with only about $10 \%$ reversibly bound to various amino acids and albumin. This non-ceruloplasmin-bound serum copper is significantly increased and represents a potentially toxic portion of the copper load in fulminant WD [7]. It is not removed by conventional dialytic therapies, which are poor in removing protein-bound substances. As albumin has specific binding sites for metals such as copper [8], albumin dialysis, which involves dialyzing blood against an albumin-containing dialysate across a semi-permeable membrane, may allow better clearance of both non-ceruloplasminbound and free copper and may play a role as a bridging therapy to liver transplantation in patients with fulminant WD.

Various methods reported to bridge to transplantation include single pass albumin dialysis (SPAD), plasma exchange (PLEX), and molecular adsorbent recirculating systems (MARS), but no consensus exists on the preferred treatment [4, 6, 9-14]. We report the effective use of SPAD alone and in combination with PLEX as a bridge to liver transplantation in 2 patients with fulminant WD. 


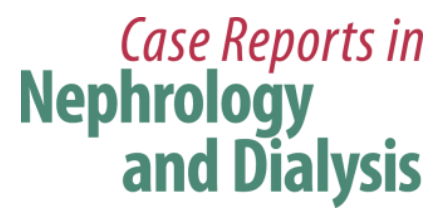

Case Rep Nephrol Dial 2019;9:55-63

DOI: $10.1159 / 000500104$

(c) 2019 The Author(s). Published by S. Karger AG, Base www.karger.com/cnd

Bakhsh et al.: SPAD and PLEX for Copper Toxicity in Wilson Disease

\section{Case Reports}

\section{Patient 1}

A 17-year-old girl with depression and anxiety disorder was admitted with fulminant hepatic failure, acute kidney injury, and Coombs-negative hemolytic anemia after she had presented with a syncopal episode and a 4-month history of generalized malaise. Her weight was $57 \mathrm{~kg}$, height $160 \mathrm{~cm}$, and body surface area $1.59 \mathrm{~m}^{2}$. She was icteric, with moderate ascites and hepatosplenomegaly. The presence of Kayser-Fleischer rings on slit lamp examination was suggestive of WD. The relevant blood work is listed in Table 1; she had low serum ceruloplasmin $(<40 \mathrm{mg} / \mathrm{L})$ and elevated serum copper $(22.3 \mu \mathrm{mol} / \mathrm{L})$ and 24 -h urine copper $(249.3 \mu \mathrm{mol} /$ day). The liver was diffusely echogenic on ultrasound. A subsequent liver biopsy revealed cirrhosis, macroregenerative nodules, and an elevated hepatic tissue copper level of $18.64 \mu \mathrm{mol} / \mathrm{g}$ of dry weight (reference range 0.16-0.55). Genetic analysis identified a pathogenic variant in the $A T P 7 B$ gene (heterozygous for c.2333G>T and c.4092_4093delGT), confirming the diagnosis of WD.

Initially, multiple red cell transfusions were required to maintain the patient's hemoglobin level. She was started on oral trientine dihydrochloride $500 \mathrm{mg}$ twice daily and zinc sulfate $50 \mathrm{mg} 3$ times daily for copper chelation.

SPAD was initiated via an 11.5-Fr double-lumen right femoral venous catheter for fluid and copper removal as a bridge to liver transplantation. We used the PRISMA ${ }^{\mathrm{TM}}$ machine with an HF $1000^{\mathrm{TM}}$ filter (polysulfone membrane; surface area $1.15 \mathrm{~m}^{2}$ ). The blood flow rate was $150 \mathrm{~mL} / \mathrm{min}$. The dialysate flow rate was $1,800 \mathrm{~mL} / \mathrm{h}$ (clearance of $2 \mathrm{~L} / 1.73 \mathrm{~m}^{2} \mathrm{BSA} / \mathrm{h}$ ) for $8 \mathrm{~h}$, before decreasing it to $900 \mathrm{~mL} / \mathrm{h}$ (clearance of $1 \mathrm{~L} / 1.73 \mathrm{~m}^{2} \mathrm{BSA} / \mathrm{h}$ ). The albumin dialysate was made by adding $900 \mathrm{~mL}$ of $25 \%$ albumin to $4.1 \mathrm{~L}$ of Prismasol $0^{\mathrm{TM}}$, with addition of 1 $\mathrm{mmol} / \mathrm{L}$ of potassium phosphate and $3 \mathrm{mmol} / \mathrm{L}$ of potassium chloride. The final dialysate solution contained $45 \mathrm{~g} / \mathrm{L}$ of albumin (albumin concentration $4.5 \%$ ), $4 \mathrm{mmol} / \mathrm{L}$ of potassium, and $1 \mathrm{mmol} / \mathrm{L}$ of phosphate. No anticoagulation was used, because of the patient's coagulopathy and concerns for citrate toxicity due to liver failure. SPAD was carried out continuously over $32 \mathrm{~h}$.

Serum copper decreased from 22.3 to $15.9 \mu \mathrm{mol} / \mathrm{L}$ (28.7\% decrease) after $28 \mathrm{~h}$ of treatment (Fig. 1). An urgent liver transplantation was recommended as the patient suffered from fulminant hepatic failure with hematological and biochemical parameters that were associated with a high risk of mortality based on the modified King's College Criteria (INR 3.7, PTT $74 \mathrm{~s}$, conjugated bilirubin $619 \mu \mathrm{mol} / \mathrm{L}$, unconjugated bilirubin $54 \mu \mathrm{mol} / \mathrm{L}$ ) [15]. She subsequently underwent successful liver transplantation on day 3 after presentation. The effectiveness of SPAD was illustrated by the decrease in serum bilirubin and stabilization of hemoglobin (Fig. 1). Her hepatic and kidney function had normalized prior to discharge.

\section{Patient 2}

A 12-year-old boy presented with a 1-week history of malaise, jaundice, lethargy, dark urine, and decreased oral intake. On presentation, he had fulminant liver failure, acute kidney injury, and Coombs-negative hemolytic anemia.

His weight was $49 \mathrm{~kg}$, height $150 \mathrm{~cm}$, and body surface area $1.43 \mathrm{~m}^{2}$. The initial physical examination revealed an icteric child with mild abdominal distention, hepatomegaly with no splenomegaly, and no apparent stigmata from chronic liver disease. A bedside ophthalmic 


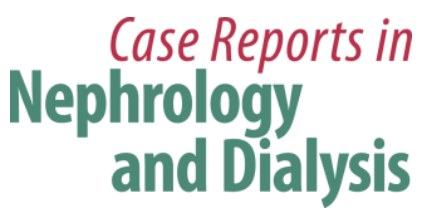

Case Rep Nephrol Dial 2019;9:55-63

DOI: $10.1159 / 000500104$

2019 The Author(s). Published by S. Karger AG, Base www.karger.com/cnd

Bakhsh et al.: SPAD and PLEX for Copper Toxicity in Wilson Disease

examination failed to reveal Kayser-Fleischer rings. The results of the initial laboratory investigations are shown in Table 1 . The patient also developed hyponatremia ( $129 \mathrm{mmol} / \mathrm{L}$ ), hypophosphatemia $(0.60 \mathrm{mmol} / \mathrm{L})$, and metabolic acidosis ( $\mathrm{pH} 7.23, \mathrm{HCO}_{3} 15 \mathrm{mmol} / \mathrm{L}, \mathrm{pCO}_{2} 36$ $\mathrm{mm} \mathrm{Hg}$ ) suggestive of a tubulopathy. High serum copper $(37.1 \mu \mathrm{mol} / \mathrm{L})$, low ceruloplasmin (67 mg/L), and elevated urine copper $(192.37 \mu \mathrm{mol} / \mathrm{L})$ were highly suggestive of WD. Genetic analysis subsequently identified a pathogenic homozygous mutation, p.N1270S in exon 18 of the $A T P 7 B$ gene, confirming the diagnosis of WD.

Initially, multiple red cell transfusions were required to maintain the patient's hemoglobin above $8 \mathrm{~g} / \mathrm{dL}$. He was started on daily oral penicillamine $250 \mathrm{mg}$ daily, which was increased to $500 \mathrm{mg}$ orally daily and oral zinc $50 \mathrm{mg}$ BID for copper chelation. Over the next 24 $\mathrm{h}$, he deteriorated clinically and was admitted to the pediatric intensive care unit. He became increasingly hypoxemic, requiring mechanical ventilation with the development of bilateral pleural effusions that necessitated drainage via chest drains. He also developed recurrent episodes of atrial fibrillation requiring cardioversion.

PLEX was started on day 2 using the Spectra OptiaTM machine with a blood prime. The replacement fluid used was with $5 \%$ albumin $(1,500 \mathrm{~mL})$ and fresh frozen plasma $(1,500 \mathrm{~mL})$ at the end to provide coagulation factors. The patient completed a total of four 1-plasma-volume exchanges over 3 days. Prophylactic calcium gluconate $(10 \mathrm{~mL}$ of $10 \%$ solution) was administered prior to each procedure to prevent hypocalcemia. No citrate toxicity or other adverse reactions were observed during the procedure.

SPAD was also initiated on day 3 ( $6 \mathrm{~h}$ after initial PLEX) via an 11.5-Fr double-lumen right femoral venous catheter to effect further copper removal, as there was a rebound in serum bilirubin with further hemolysis after completion of the first PLEX as well as worsening oliguria $(0.4 \mathrm{~mL} / \mathrm{kg} / \mathrm{h})$ despite treatment with diuretics, and metabolic acidosis ( $\mathrm{pH} \mathrm{7.22,} \mathrm{bicar-}$ bonate $13 \mathrm{mmol} / \mathrm{L}$ ), which necessitated renal replacement therapy (peak creatinine 185 $\mu \mathrm{mol} / \mathrm{L}$; revised bedside Schwartz eGFR $30 \mathrm{~mL} / \mathrm{min} / 1.73 \mathrm{~m}^{2}$ ). We used the PRISMATM machine with an HF 1000 filter as with the first patient. The blood flow rate was $150 \mathrm{~mL} / \mathrm{min}$ and the dialysate flow rate was $500 \mathrm{~mL} / \mathrm{h}$ (clearance of $750 \mathrm{~mL} / 1.73 \mathrm{~m}^{2} \mathrm{BSA} / \mathrm{h}$ ). The albumin dialysate composition was identical to that used for patient 1 . No anticoagulation was used, because of the coagulopathy and liver failure. SPAD was continued for 3 days before it was discontinued on day 6, when the child received a successful liver transplant.

Serum copper decreased from 48.7 to $25.8 \mu \mathrm{mol} / \mathrm{L}$ ( $47 \%$ decrease) after the first session of PLEX. Sixteen hours after SPAD had been added to the initial PLEX, the serum copper level was $35.5 \mu \mathrm{mol} / \mathrm{L}$. Unfortunately, the serum copper level had not been checked prior to commencing SPAD to assess if there was any rebound after PLEX. Serum copper then fell to 21.5 $\mu \mathrm{mol} / \mathrm{L}$ (39.4\% decrease) after the second session of PLEX had been added to the ongoing SPAD. The mean cumulative decrease in copper was $66.7 \%$, and the serum copper level was $16.2 \mu \mathrm{mol} / \mathrm{L}$ after 4 sessions of PLEX in combination with SPAD (Fig. 2). The effectiveness of the SPAD-PLEX combination is illustrated by the rapid removal of copper (from 35.5 to 16.2 $\mu \mathrm{mol} / \mathrm{L} ; 54.4 \%$ decrease), without a significant increase in rebound, corresponding to a normalization of serum bilirubin and stabilization of hemoglobin (Fig. 2). The metabolic acidosis also gradually improved over the course of SPAD treatment and normalized after $24 \mathrm{~h}(\mathrm{pH}$ 7.45 , bicarbonate $28 \mathrm{mmol} / \mathrm{L}$ ). Urgent liver transplantation was recommended as the patient suffered from fulminant hepatic failure with hematological and biochemical parameters that were associated with a high risk of mortality based on the modified King's College Criteria 


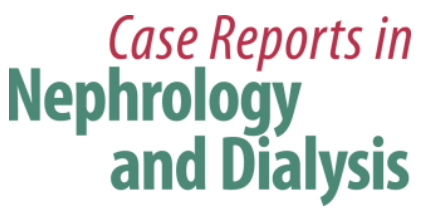

\begin{tabular}{l|l} 
Case Rep Nephrol Dial 2019;9:55-63 \\
\hline DOI: 10.1159/000500104 & $\begin{array}{l}\text { @ 2019 The Author(s). Published by S. Karger AG, Basel } \\
\text { www.karger.com/cnd }\end{array}$
\end{tabular}

Bakhsh et al.: SPAD and PLEX for Copper Toxicity in Wilson Disease

(INR 3.7, PTT 51 s, conjugated bilirubin $691 \mu \mathrm{mol} / \mathrm{L}$, unconjugated bilirubin $115 \mu \mathrm{mol} / \mathrm{L}$ ) [15]. He underwent successful liver transplantation on day 6.

The explanted liver weighed 1,400 g, and the capsule was brown-green in color and nodular in appearance and had microscopic features of cirrhosis. A tissue copper quantification test showed a level of $9.79 \mu \mathrm{mol} / \mathrm{g}$ dry weight (reference range $0.16-0.55$ ). The patient's postoperative course was unremarkable.

\section{Discussion}

SPAD is a form of albumin dialysis which utilizes a standard continuous hemodialysis system with the addition of albumin to a standard dialysate. The albumin-containing dialysate allows for improved clearance of protein-bound substances like non-ceruloplasmin-bound copper, which is elevated in Wilsonian liver failure [16]. It is one of four methods available to provide extracorporeal liver support, the others being MARS, the Prometheus dialysis system, and PLEX combined with hemodialysis [11]. While the utility of MARS and the Prometheus dialysis system requires the added cost of purchasing specific new equipment and staff training, SPAD is not difficult to set up and does not require special filters/adsorbers or specific new equipment. Many members of staff within intensive care units require little re-training, as they are already familiar with the setup for continuous venovenous hemodiafiltration. Several case reports have reported the efficacy of using SPAD as supportive treatment to successfully bridge patients with fulminant Wilsonian liver failure to liver transplantation [4, 9].

Unlike MARS, where the albumin solution is regenerated by removing protein-bound substances through an activated charcoal column and an anion exchange resin, the albumin dialysate in SPAD is discarded after a single pass, necessitating a large supply of albumin [8]. One strategy to conserve albumin and limit the cost of SPAD would be to reduce the clearance, and the slower dialysate flow rates may improve dissociation of copper off binding sites and across the membrane. Although the MARS has been used successfully to bridge patients with WD to liver transplantation, analysis of the albumin dialysate in one of the patients reported on by Sen et al. [17] suggested that the MARS was saturated with copper after the initial few hours, with no significant copper removal thereafter, presumably as there is no cation exchanger in the circuit, potentially limiting its effectiveness for the treatment of copper-related hemolysis. In contrast, SPAD has a potential advantage based on continuous removal of copper without saturation of the albumin-binding capacity. In patient 1, SPAD with a 4.5\% (45 g/L) albumin dialysate reduced serum copper levels by $28.7 \%$ and stabilized hemolysis and multiorgan failure, bridging to a successful liver transplantation.

PLEX is useful for removing protein-bound substances that are poorly removed via conventional dialysis. An added advantage in this clinical situation is the replenishment of coagulation factors with plasma replacement. The efficacy of PLEX in removing excess copper in patients with fulminant WD has been illustrated in several case reports $[6,10,12,13,18-21]$. In our second patient, serum copper levels were reduced by $47 \%$ after the first PLEX, confirming its efficacy. However, significant acute kidney injury in a hemodynamically unstable child necessitated the initiation of continuous renal replacement therapy, which influenced our decision to add SPAD to effect a more sustained reduction in serum copper levels. Unfortunately, the serum copper level had not been checked prior to commencing SPAD to assess for a 


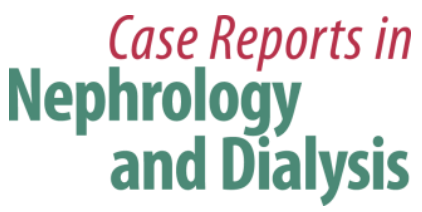

\begin{tabular}{l|l}
\hline Case Rep Nephrol Dial 2019;9:55-63 \\
\hline DOI: 10.1159/000500104 & $\begin{array}{l}\text { (c) 2019 The Author(s). Published by S. Karger AG, Basel } \\
\text { www.karger.com/cnd }\end{array}$
\end{tabular}

potential rebound in serum copper level after PLEX. In combination, a sustained 54.4\% reduction of serum copper levels was achieved, together with stabilization of hemolysis, bilirubin levels, and multiorgan failure for 4 days, bridging the patient to a successful liver transplantation. As the patient also had a concomitant acute kidney injury, the addition of SPAD allowed for an improvement of his fluid and acid-base management.

Our report has limitations, of course, due to its retrospective nature, the fact that blood levels were taken opportunistically, and lack of generalizability, as is common with all case reports. However, in these rare cases, the importance of sharing clinical experiences is well recognized.

In these 2 patients, we demonstrated the clinical utility of SPAD alone and SPAD in combination with PLEX as potentially effective measures to reduce serum copper levels, stabilize hemolysis, and improve the clinical status of patients with fulminant WD as a bridge to liver transplantation; however, further clinical studies are needed to confirm its efficacy. PLEX is widely available and effective in reducing serum copper levels. However, rebound rises in serum copper levels between exchanges can occur. The addition of SPAD may prevent such rebound and has the added advantage of removing small-molecular-weight solutes that cause hepatic coma, managing fluid overload, and correcting electrolyte and acid-base abnormalities [22].

\section{Statement of Ethics}

The authors have no ethical conflicts to disclose. Consent was obtained from the parents of the patients for publication of the case reports.

\section{Disclosure Statement}

The authors have no conflicts of interest to disclose.

\section{Author Contributions}

S.B. and C.W.T. contributed equally to conceptualizing, drafting, reviewing, and revising of the manuscript. E.A.H. and D.G.N. contributed to the conception and design of the report, and critically reviewed the manuscript. All authors approved the final manuscript as submitted and agree to be accountable for all aspects of the work.

\section{References}

1 Tanzi RE, Petrukhin K, Chernov I, Pellequer JL, Wasco W, Ross B, et al. The Wilson disease gene is a copper transporting ATPase with homology to the Menkes disease gene. Nat Genet. 1993 Dec;5(4):344-50.

2 Taly AB, Meenakshi-Sundaram S, Sinha S, Swamy HS, Arunodaya GR. Wilson disease: description of 282 patients evaluated over 3 decades. Medicine (Baltimore). 2007 Mar;86(2):112-21. 


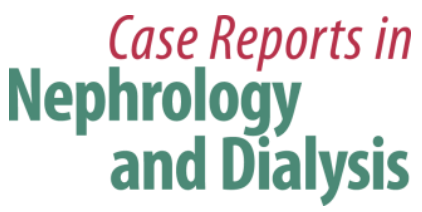

Case Rep Nephrol Dial 2019;9:55-63

Bakhsh et al.: SPAD and PLEX for Copper Toxicity in Wilson Disease

3 Ferenci P. Review article: diagnosis and current therapy of Wilson's disease. Aliment Pharmacol Ther. 2004 Jan;19(2):157-65.

4 Collins KL, Roberts EA, Adeli K, Bohn D, Harvey EA. Single pass albumin dialysis (SPAD) in fulminant Wilsonian liver failure: a case report. Pediatr Nephrol. 2008 Jun;23(6):1013-6.

5 Wiggelinkhuizen M, Tilanus ME, Bollen CW, Houwen RH. Systematic review: clinical efficacy of chelator agents and zinc in the initial treatment of Wilson disease. Aliment Pharmacol Ther. 2009 May;29(9):947-58.

6 Hilal T, Morehead RS. Fulminant Wilson's Disease Managed with Plasmapheresis as a Bridge to Liver Transplant. Case Rep Med. 2014;2014:672985.

7 Roberts EA, Schilsky ML; Division of Gastroenterology and Nutrition, Hospital for Sick Children, Toronto, Ontario, Canada. A practice guideline on Wilson disease. Hepatology. 2003 Jun;37(6):1475-92.

8 Mitzner S, Klammt S, Stange J, Schmidt R. Albumin regeneration in liver support-comparison of different methods. Ther Apher Dial. 2006 Apr;10(2):108-17.

9 Kreymann B, Seige M, Schweigart U, Kopp KF, Classen M. Albumin dialysis: effective removal of copper in a patient with fulminant Wilson disease and successful bridging to liver transplantation: a new possibility for the elimination of protein-bound toxins. J Hepatol. 1999 Dec;31(6):1080-5.

10 Verma N, Pai G, Hari P, Lodha R. Plasma exchange for hemolytic crisis and acute liver failure in Wilson disease. Indian J Pediatr. 2014 May;81(5):498-500.

11 Schaefer B, Schmitt CP. The role of molecular adsorbent recirculating system dialysis for extracorporeal liver support in children. Pediatr Nephrol. 2013 Sep;28(9):1763-9.

12 Reynolds HV, Talekar CR, Bellapart JB, Leggett BA, Boots RJ. Therapeutic plasma exchange as de-coppering technique in intensive care for an adult in a Wilson's crisis. Anaesth Intensive Care. 2013 Nov;41(6):811-2.

13 Morgan SM, Zantek ND. Therapeutic plasma exchange for fulminant hepatic failure secondary to Wilson's disease. J Clin Apher. 2012 Nov;27(5):282-6.

14 Kortgen A, Rauchfuss F, Götz M, Settmacher U, Bauer M, Sponholz C. Albumin dialysis in liver failure: comparison of molecular adsorbent recirculating system and single pass albumin dialysis - a retrospective analysis. Ther Apher Dial. 2009 Oct;13(5):419-25.

15 McPhail MJ, Farne H, Senvar N, Wendon JA, Bernal W. Ability of King's College Criteria and Model for EndStage Liver Disease Scores to Predict Mortality of Patients With Acute Liver Failure: A Meta-Analysis. Clin Gastroenterol Hepatol. 2016 Apr;14(4):516-25.e5; quiz e43-e45.

16 Karvellas CJ, Gibney N, Kutsogiannis D, Wendon J, Bain VG. Bench-to-bedside review: current evidence for extracorporeal albumin dialysis systems in liver failure. Crit Care. 2007;11(3):215-22.

17 Sen S, Felldin M, Steiner C, Larsson B, Gillett GT, Olausson M, et al. Albumin dialysis and molecular adsorbents recirculating system (MARS) for acute Wilson's disease. Liver Transpl. 2002 Oct;8(10):962-7.

18 Kiss JE, Berman D, Van Thiel D. Effective removal of copper by plasma exchange in fulminant Wilson's disease. Transfusion. 1998 Apr;38(4):327-31.

19 Jhang JS, Schilsky ML, Lefkowitch JH, Schwartz J. Therapeutic plasmapheresis as a bridge to liver transplantation in fulminant Wilson disease. J Clin Apher. 2007 Feb;22(1):10-4.

20 Asfaha S, Almansori M, Qarni U, Gutfreund KS. Plasmapheresis for hemolytic crisis and impending acute liver failure in Wilson disease. J Clin Apher. 2007;22(5):295-8.

21 Sauer IM, Goetz M, Steffen I, Walter G, Kehr DC, Schwartlander R, et al. In vitro comparison of the molecular adsorbent recirculation system (MARS) and single-pass albumin dialysis (SPAD). Hepatology. 2004 May;39(5):1408-14.

22 van de Kerkhove MP, Hoekstra R, Chamuleau RA, van Gulik TM. Clinical application of bioartificial liver support systems. Ann Surg. 2004 Aug;240(2):216-30. 
Case Reports in

Nephrology

and Dialysis
Case Rep Nephrol Dial 2019;9:55-63

DOI: 10.1159/000500104 (c) 2019

Bakhsh et al.: SPAD and PLEX for Copper Toxicity in Wilson Disease

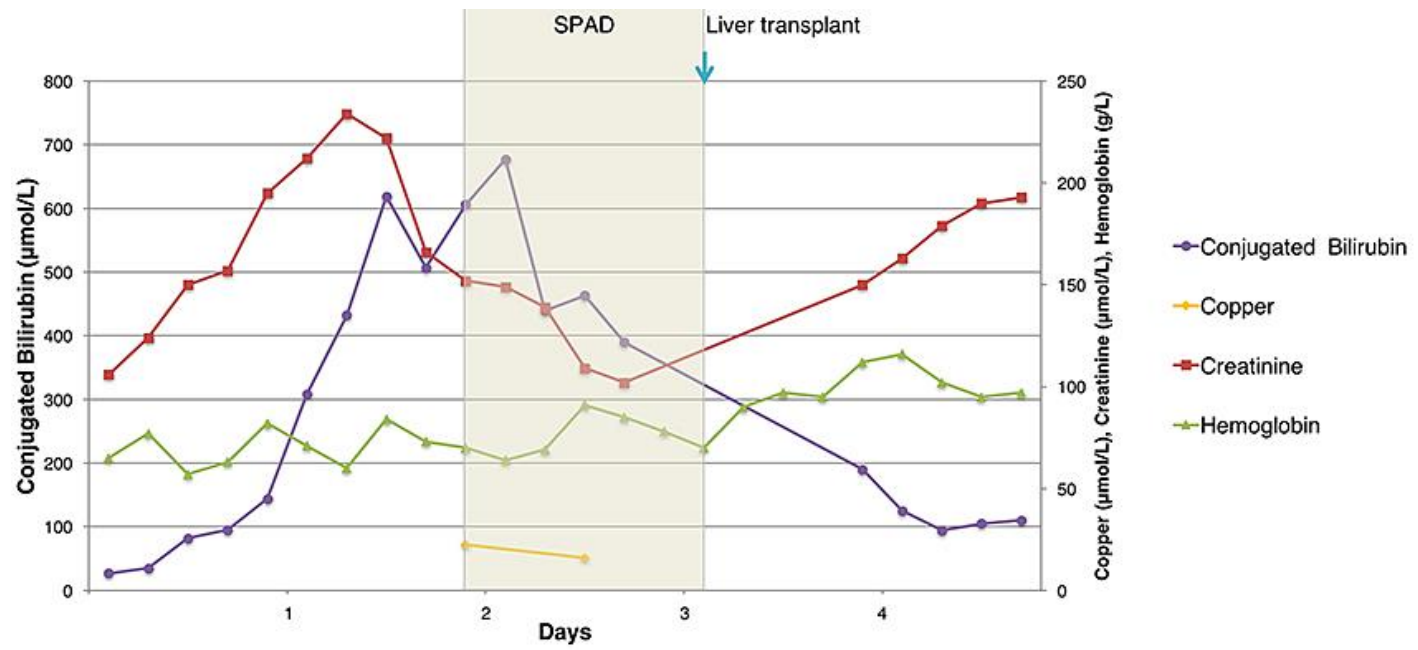

Fig. 1. Course of treatment and progress for patient 1.

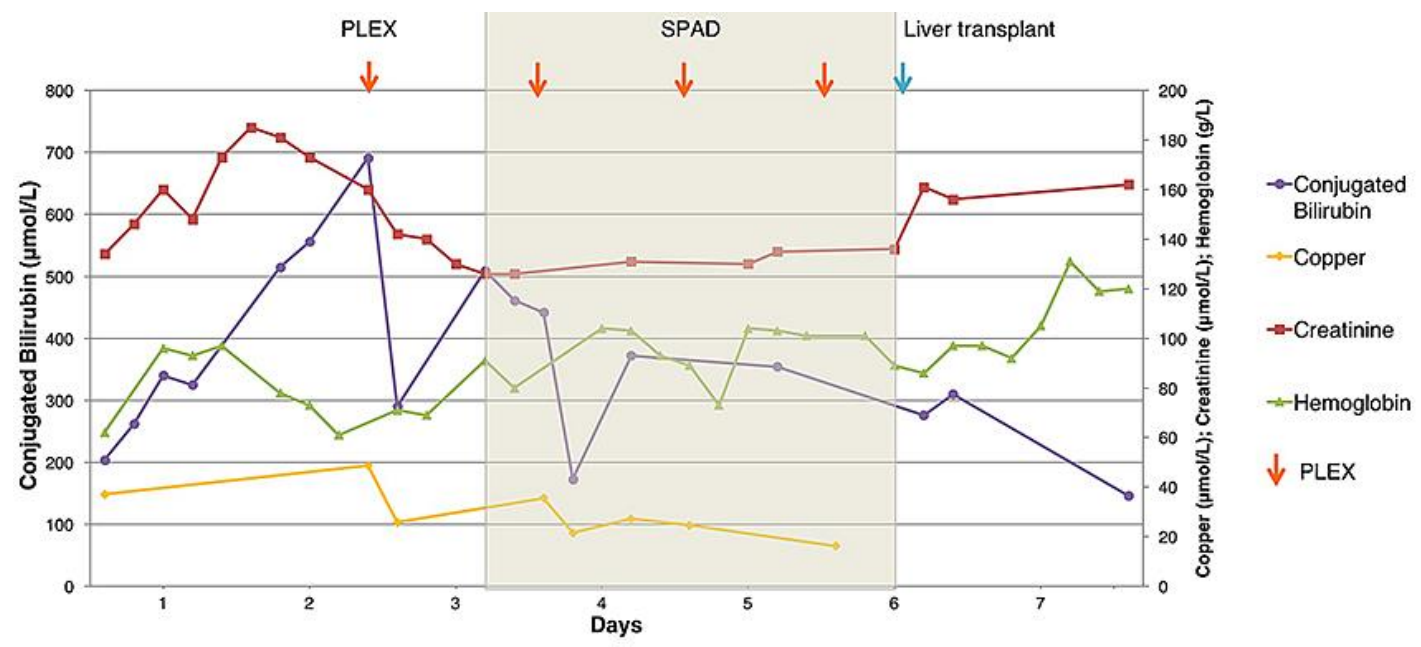

Fig. 2. Course of treatment and progress for patient 2 . 

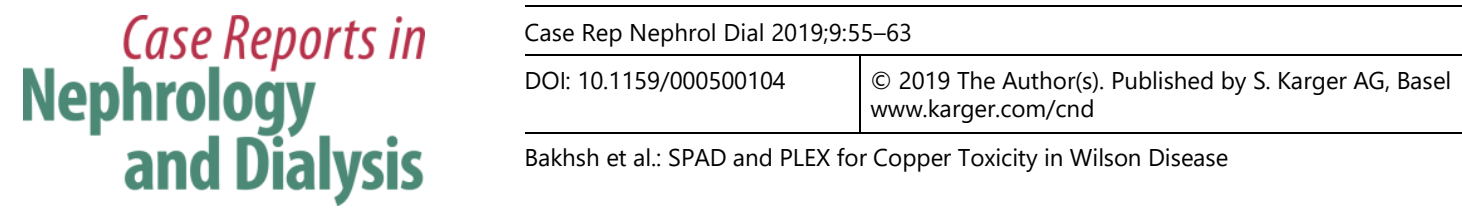

Table 1. Examination results at presentation for both patients

\begin{tabular}{llll}
\hline Examinations & Patient 1 & Patient 2 & Normal ranges \\
\hline Hb, g/L & 65 & 62 & $120-160$ \\
Platelet count, $\times 10^{9} / \mathrm{L}$ & 214 & 130 & $150-400$ \\
White blood cell count, $\times 10^{9} / \mathrm{L}$ & 14.1 & 18.3 & $4-10$ \\
Lactate dehydrogenase, U/L & 1,451 & n/a & $340-670$ \\
Coombs test & negative & negative & - \\
Conjugated bilirubin, $\mu \mathrm{mol} / \mathrm{L}$ & 27 & 204 & $0-2$ \\
Unconjugated bilirubin, $\mu \mathrm{mol} / \mathrm{L}$ & 75 & 85 & $<7$ \\
AST, U/L & 133 & 228 & $0-36$ \\
ALT, U/L & 19 & 34 & $0-40$ \\
GGT, U/L & 165 & 192 & $0-45$ \\
Alkaline phosphatase, U/L & 32 & $<20$ & $200-630$ \\
Albumin, g/L & 22 & 21 & $32-56$ \\
INR & 1.6 & 2.4 & $0.8-1.2$ \\
Creatinine, $\mu$ mol/L & 106 & 134 & $<79$ \\
Serum copper, $\mu \mathrm{mol} / \mathrm{L}$ & 22.3 & 37.1 & $12.6-19$ \\
Serum ceruloplasmin, $\mathrm{mg} / \mathrm{L}$ & $<40$ & 67 & $242-396$ \\
Urine copper, $\mu$ mol/L & 249.3 & 192.37 & $0.04-0.19$ \\
\hline
\end{tabular}

